\title{
Blood Pressure Management in Acute Ischemic Stroke
}

\author{
Dariusz Gąsecki ${ }^{1}$ • Mariusz Kwarciany ${ }^{1} \cdot$ Kamil Kowalczyk $^{1} \cdot$ Krzysztof Narkiewicz $^{2}$ • Bartosz Karaszewski ${ }^{1}$
}

Published online: 10 December 2020

(C) The Author(s) 2020

\begin{abstract}
Purpose of Review Abrupt blood pressure (BP) rise is the most common clinical symptom of acute ischemic stroke (AIS). However, BP alterations during AIS reflect many diverse mechanisms, both stroke-related and nonspecific epiphenomena, which change over time and across patients. While extremes of BP as well as high BP variability have been related with worse outcomes in observational studies, optimal BP management after AIS remains challenging.

Recent Findings This review discusses the complexity of the factors linking BP changes to the clinical outcomes of patients with AIS, depending on the treatment strategy and local vessel status and, in particular, the degree of reperfusion achieved. The evidence for possible additional clinical markers, including the presence of arterial hypertension, and comorbid organ dysfunction in individuals with AIS, as informative and helpful factors in therapeutic decision-making concerning BP will be reviewed, as well as recent data on neurovascular monitoring targeting person-specific local cerebral perfusion and metabolic demand, instead of the global traditional parameters (BP among others) alone.

Summary The individualization of BP management protocols based on a complex evaluation of the homeostatic response to focal cerebral ischemia, including but not limited to BP changes, may be a valuable novel goal proposed in AIS, but further trials are warranted.
\end{abstract}

Keywords Blood pressure $\cdot$ Hypertension $\cdot$ Acute ischemic stroke $\cdot$ Management

\section{Introduction}

Stroke is globally a leading cause of mortality and long-term disability in adults. Even though the prevalence and death rate due to stroke have decreased over the last years, the overall burden remains high, and the absolute number of people affected continues to increase $[1,2]$. Acute ischemic stroke (AIS) accounts for approximately $70-85 \%$ of all strokes worldwide.

AIS is caused by a critical reduction in blood flow to the brain. Cerebral blood flow (CBF) is almost totally arrested in the core region of the insult, which leads to neuronal death

This article is part of the Topical Collection on Guidelines / Clinical Trials/Meta-Analysis

Dariusz Gąsecki

dgasecki@gumed.edu.pl

1 Department of Adult Neurology, Medical University of Gdańsk, ul, Dębinki 7, 80-952 Gdańsk, Poland

2 Department of Hypertension and Diabetology, Medical University of Gdańsk, ul, Dębinki 7, 80-952 Gdańsk, Poland within minutes. The tissue surrounding the core is severely hypoperfused and functionally impaired but still viable. This zone, called the penumbra, is at high risk of infarction. It permits cell survival for a certain period of time; however, it is extremely vulnerable to CBF fluctuations, which depend on both local and global factors, such as cerebral vasoreactivity or collaterals and systemic components, especially blood pressure (BP). Therefore, the salvation of the ischemic penumbra is the holy grail of vascular neurology. There are two fundamental factors which allow this aim: (i) early recanalization and reperfusion and (ii) the maintenance of CBF before reperfusion occurs.

Strategies aiming at fast reperfusion, including intravenous thrombolysis (IVT) and mechanical thrombectomy (MT) within 4.5 and $6 \mathrm{~h}$ (in selected patients, up to 24), respectively, from the stroke onset, remain the most effective therapeutic methods in standard care. However, the proper management of multiple clinical problems other than - or secondary to-arterial occlusion is also significantly associated with the final outcome. In this regard, hemodynamics plays a special role.

$\mathrm{BP}$ is one of the most important modifiers of vascular function and organ perfusion, and its abnormalities are related to 
vascular dysfunction, with cerebral circulation appearing as one of the most susceptible to BP dysregulations.

Ischemic stroke is a consequence of a variety of pathological conditions, resulting from either systemic cardiovascular (CV) diseases or primary cerebrovascular diseases, which, in the great majority, may be considered as hypertensive or hypertension related. Therefore, a large proportion of AIS is a consequence of chronic hypertension (HT).

On the other hand, acute BP elevation is one of the most common phenomena observed in the first hours and days after AIS onset, which potentially strongly influences clinical decisions and modifies the risk of acute complications.

There is a growing body of evidence that BP may be an important factor related to stroke outcome; however, the available evidence shows conflicting results. Indeed, BP elevation after stroke, being a common aspect of many processes, is rather descriptive, if not an epiphenomenon of a plethora of influencing factors, and further data is needed to predict stroke outcome.

We believe that the associations of BP in the acute phase of stroke with its clinical course should be analyzed as part of a long-standing process, which might begin even many years before the event, rather than as an acute phenomenon occurring only in the first days after the disease onset. It seems to us that a paradigm shift in the management of BP in AIS is needed: from simplistic, based just on sole BP values, to more complex, including the identification and management of compensatory mechanisms, modified by chronic diseases, especially HT and, what is even more relevant, adjusted to local hemodynamic and metabolic demands in the ischemic area. The aim of this review is to discuss recent changes in the field of the influence of BP and its management in AIS and to present the perspectives of a complex approach to this important aspect of AIS care.

\section{Pre-stroke Blood Pressure}

Pre-stroke HT is reported in $30-80 \%$ of AIS patients and, according to the INTERSTROKE study, accounts for approximately 32 to $45 \%$ of the population-attributable risk of AIS. Moreover, hypertension has been shown to be the main contributor to stroke mortality [3]. The prevalence of HT is the highest among patients with large artery and small vessel pathologies and less common in patients with cardioembolic stroke [4]. It is noteworthy that the frequency of hypertension increases with age, regardless of the stroke subtype [4].

It is clear that the incidence and mortality in AIS are associated with $\mathrm{BP} \geq 140 / 90 \mathrm{mmHg}$ (hypertension), but the risk also increases when BP exceeds values as low as 115/ $75 \mathrm{mmHg}$, especially when such values occurred early in life (higher BP load). Indeed, even prehypertension infers a greater risk of stroke than optimal BP levels [5]. Thus, the thresholds for defining HT dichotomously as a risk factor for stroke should be reconsidered.

Although sustained hypertension clearly increases the incidence of stroke, also a transient and repetitive rise in BP, referred to as BP variability (BPV), both short-term (daynight) and long-term (seasonal or visit-to-visit) BPV are related to an increased risk of stroke [6]. Moreover, an abnormal BP circadian course, characterized by an insufficient nocturnal systolic BP (SBP) decrease (i.e., < $10 \%$ ) compared to daily values, was proven to be associated with an increased risk of stroke [7]. Morning surge, characterized by an extreme SBP rise during the wake-up time, appears to be of particular relevance and represents subpopulations at an elevated risk of ischemic stroke and other stroke subtypes [8••].

Racial disparities in the burden of hypertension-related diseases may account for stroke incidence. African Americans as well as sub-Saharan Africans are known to have a higher prevalence of HT, nocturnal HT, and a non-dipping BP profile which starts earlier than in white people $[9,10]$. They also have higher cardiovascular risk than white people, including ischemic stroke, which is largely driven by nocturnal BP [11].

A steeper association of BP with stroke among Asians than among European populations was also observed [12]. A similar pattern was reported in Latin American countries, with the mean patient age at stroke onset being approximately 10 years younger than in high-income countries (e.g., North America) [13].

Based on the aforementioned, it is highly probable that an excess risk of stroke, partially beyond pure office BP values, may exist in the majority of ethnic groups worldwide.

\section{Blood Pressure in Acute Stroke}

In the acute phase of AIS, increased BP (often reflecting a transient reaction thus called acute hypertensive response, AHR) is observed in approximately $75 \%$ of patients [14]. AHR is usually at its highest within the first hours after stroke onset, then gradually declines [15], and usually settles within the first 7-10 days after stroke onset $[16,17]$.

Interestingly, in some patients (particularly younger ones), the absolute values of increased BP remain within "normotensive" limits. The mechanisms of this clinical setting are not clear and probably very heterogenous.

AHR is a phenomenon caused by a myriad of factors [18]. On one hand, it might be related to preexisting conditions, including inadequately treated or undiagnosed hypertension [19-22] or diabetes mellitus [23]. On the other hand, it may be linked to stroke-related factors such as damage to the brain regions involved in autonomic regulation [24] or secondary sympathetic adrenomedullary pathway activation due to the stroke itself [25-28]. 
Frequently, it is associated with AIS consequences, e.g., urine retention, infection, cerebral edema, headache [29, 30], or stress related to hospitalization [21,31].

Early recanalization can be achieved in up to $30 \%$ of patients treated with IVT alone [32], and the rate may increase to even $80-90 \%[33,34]$ in patients treated with MT. But even in a best-case scenario, only up to $50 \%$ of patients who receive this treatment may achieve functional independence, partially due to the fact that the core of the insult is already too large at the time of reperfusion [35]. Recently, however, it has been postulated that tissue outcome following AIS is associated with multiple factors and mechanisms, other than those directly related to local hypoperfusion, the potential outcome-based significance of which is illustrated by a recently described reverse mismatch phenomenon [36-38].

This partially depends on individual factors such as vascular compliance or collaterals [39]. The latter are crucial in maintaining CBF in the penumbra, distally from the occluded artery [40]. Collaterals are associated with lower infarct volume growth and thus with better functional outcome [41]. As it has been recently shown in patients undergoing endovascular treatment, the odds for a good clinical outcome were threefold higher in patients with good collaterals than in patients with absent collaterals [42]. However, collateral blood flow not only depends on individual anatomy but also on adaptive features like cerebral autoregulation (CA). Studies indicate that dynamic CA may be damaged by AIS, irrespective of the stroke subtype, for up to $96 \mathrm{~h}$, and remain abnormal for at least 1-2 weeks after the stroke [43]. Previous studies on static CA showed that it may remain preserved in AIS [44]. In the case of dysregulated $\mathrm{CA}, \mathrm{CBF}$ within the penumbra depends on systemic BP [45]. Within recent years, the relationship between blood pressure and collateral blood flow has been investigated. It is postulated that BP may influence collateral blood flow in AIS.

On the other hand, BP values in the acute phase of stroke may reflect the individual efficacy of local (collaterals) and systemic (volemia, cardiac output, vascular reaction) compensatory mechanisms.

Sufficient collateral blood flow results in slower [46] and smaller ischemic lesion growth [47].

The majority of studies indicate that higher acute phase BP is associated with better collaterals in ischemic stroke patients [48-52]. There is, however, some evidence from a few studies showing that lower BP may favor better pial collateral recruitment [53].

The majority of studies indicate that higher BP may be an important factor improving cerebral blood flow in the penumbra, however, under one major condition-reperfusion. A study by Hong et al. suggests that higher BP may result in a smaller infarct volume but only in patients with major reperfusion. In the case of reperfusion failure, sustained high BP may result in increased infarct growth and an unfavorable outcome $[54 \cdot \bullet]$.
BP patterns may also influence outcomes even in patients with poor collaterals. Lower BP fluctuations after reperfusion were shown to be associated with better long-term outcomes in patients undergoing MT.

\section{Blood Pressure Management}

\section{Pre-hospital Phase}

The proper management in the pre-hospital phase is decisive in the treatment of ischemic stroke. As recanalization and reperfusion are crucial factors influencing longterm functional outcome [55], shortening of the onset-torecanalization time should be the main aim of prehospital treatment. However, since recanalization may not result in a clinical improvement in up to half of patients [35], one should not neglect other potentially modifiable conditions, such as blood oxygenation, glucose level, body temperature, and BP. According to the current American Heart Association (AHA) guidelines [56・• and European Stroke Organization (ESO) Consensus Statements and Recommendations [57], both published in 2018, BP should not be lowered in the prehospital phase. This has been confirmed by recently published results of the RIGHT-2 trial [58・•], which showed that in patients with a presumed stroke and elevated BP, pre-hospital antihypertensive treatment with transdermal glyceryl trinitrate (GTN) does not improve functional outcome. However, this study, together with previous smaller trials [59], showed that ambulance-based studies are feasible and needed. A new study assessing transdermal GTN in the hyperacute phase of ischemic stroke is currently ongoing [60].

\section{Intrahospital Phase}

Both the AHA and ESO guidelines indicate that in patients who are not qualified for either IVT or MT, BP should not be lowered, unless it exceeds 220/ $120 \mathrm{mmHg}$. It is, however, highlighted that patients with AIS, presenting symptoms of other severe, acute comorbidities (e.g., acute coronary event, acute heart failure, aortic dissection, or preeclampsia/eclampsia), may require an emergency BP reduction. It is underlined that a BP reduction should be careful and individualized since an exaggerated drop in BP can result in complications, such as stroke progression or acute kidney injury [56••, 57]. According to the AHA, a reasonable goal is a $15 \%$ reduction in the initial BP [56••]. To date, no BP reduction strategy has been shown to be superior. 


\section{Specific Treatment}

\section{Intravenous Thrombolysis}

According to the current AHA and ESO guidelines, patients who are eligible for treatment with intravenous thrombolysis (IVT) should have their BP carefully lowered so that their SBP is $<185 \mathrm{mmHg}$ and their diastolic BP (DBP) is < $110 \mathrm{mmHg}$ before IVT is initiated and $<180 / 105 \mathrm{mmHg}$ during the first $24 \mathrm{~h}$ after the treatment $[56 \bullet \bullet, 57]$. These thresholds are extrapolated from thrombolysis trials in myocardial infarction as well as from the National Institute of Neurologic Disorders (NINDS) t-PA Trial [61].

However, BP levels higher than those recommended are observed in up to $50 \%$ of patients who are eligible for IVT [62].

It has been retrospectively shown that higher BP significantly increased the risk of hemorrhagic transformation [61, 63]. The risk increased linearly, being four times higher in patients with SBP $>170 \mathrm{mmHg}$ compared to those at 141$150 \mathrm{mmHg}$ [64].

Moreover, it also increased in patients with higher BP variability [64-66]. This is in line with a finding that a cumulative decline in SBP $>50 \mathrm{mmHg}$ or an acute drop of $>30 \mathrm{mmHg}$ was associated with a decreased likelihood of a favorable outcome. It is noteworthy that an acute drop in SBP, DBP, or MBP $>60 \mathrm{mmHg}$ was associated with an increased risk of death [67].

The exact BP at which the risk of hemorrhage after intravenous thrombolysis increases is rather individual and probably depends on BP per se but also on other acute and chronic factors $[68 \cdot \bullet$.

Recently, ENCHANTED, a randomized control trial (RCT) conducted in patients treated with IVT, showed a reduced risk of hemorrhagic transformation in patients treated intensively (target systolic blood pressure at 130 $140 \mathrm{mmHg}$ ) when compared to patients treated according to the guidelines over the first $72 \mathrm{~h}$ after stroke onset. This, however, did not translate into an improved clinical outcome $[68 \bullet \bullet$.

In a recent meta-analysis, Malhotra et al. evaluated the impact of pre- and postthrombolysis BP values on clinical outcome in over 56,000 AIS patients. In this group, a higher pre- and posttreatment SBP was associated with a higher risk of symptomatic intracerebral hemorrhage (sICH).

Moreover, elevated pre- and postinfusion BP was associated with worse long-term functional outcome, even after adjustment for potential confounders [69•].

Another interesting finding of Malhotra's meta-analysis is that higher mean pre-treatment SBP levels were recorded in AIS patients with proximal intracranial occlusion who did not achieve tissue plasminogen activator-induced recanalization. This suggests that elevated SBP might be a surrogate of increased baseline thrombus burden or impaired endogenous fibrinolysis [69•].

\section{Mechanical Thrombectomy}

Since 2015, mechanical thrombectomy has been a standard of treatment for ischemic stroke patients with anterior circulation large artery occlusions. In patients undergoing MT, and who have not received IVT, both the AHA and ESO recommend maintaining BP at $\leq 185 / 110 \mathrm{mmHg}$ before the procedure, as it was in 5 of 6 RCTs that demonstrated clinical benefits from MT with stent retrievers up to $6 \mathrm{~h}$ from stroke onset (REVASCAT [70], SWIFT PRIME [71], EXTEND-IA [72], THRACE [73], and MR CLEAN [74]) [56••, 57]. It is suggested to maintain BP at $\leq 180 / 105 \mathrm{mmHg}$ during, and for the $14 \mathrm{~h}$ after, the procedure, regardless of whether or not the recanalization has been achieved [56••, 57]. These guidelines, however, are not based on strong, scientifically proven data. There are, however, several new studies which have addressed the problem of BP treatment on functional outcome in patients undergoing MT. It has been shown that either pre-, intra-, and postprocedural low and high BP and BP fluctuations may negatively influence outcome in this group.

The post hoc analysis of MR CLEAN demonstrated a Ushaped relationship between baseline SBP and poor functional outcome. The most favorable BP was $120 \mathrm{mmHg}$, and a $21 \%$ increase in the relative risk of hemorrhage for every $10 \mathrm{mmHg}$ above this value was shown [75].

This is in line with an analysis of baseline BPs from over 1300 patients enrolled in the Endovascular Treatment in Ischemic Stroke registry. In this group, there was a higher risk of mortality of 3.78 and 1.81 times for SBP $<110 \mathrm{mmHg}$ and $>180 \mathrm{mmHg}$, respectively, compared with SBP 150 $160 \mathrm{mmHg}$ as a reference [76-78].

Intraprocedural BP is another important hemodynamic factor influencing outcome in patients undergoing MT. In a large study, patients with a favorable outcome presented moderately elevated SBP (average maximal SBP $164 \mathrm{mmHg}$ ) compared with those with an unfavorable outcome (average maximal SBP $181 \mathrm{mmHg}$ ) [79]. On the other hand, intraprocedural hypotension is a strong predictor of poor outcome. In a study by Lowhagen Henden et al., a mean BP (MBP) fall of $>40 \%$ from the baseline was an independent predictor of an unfavorable neurological outcome, in addition to well-established risk factors such as a high baseline NIH Stroke Scale (NIHSS) or a lack of successful recanalization [80]. The results have been confirmed by more recent studies [81, 82].

One of the most important factors influencing blood pressure levels during the MT procedure is anesthesia. In recent years, conscious sedation (CS) has been preferred over general anesthesia (GA) as it was shown to be related with better functional outcome and decreased mortality [83]. This was mainly related to the effect GA may have on hemodynamics. 
Among MR CLEAN patients, the use of GA was associated with larger drops in MBP and longer episodes of hypotension [84]. However, CS also carries a risk of hypotension. In a study by Wahlin et al., among patients treated with MT under CS, an MBP drop of $\geq 10 \%$ was associated with the highest risk of poor outcome. $\mathrm{MBP}<85 \mathrm{mmHg}$ before reperfusion, and every $10 \mathrm{mmHg}$ a drop in mean arterial pressure to below $100 \mathrm{mmHg}$ were also associated with a worse prognosis [85].

Recent data from prospective trials can contribute to a change in everyday practice. The GOLIATH, SIESTA, and AnSTROKE studies showed no differences in the clinical effect, regardless of the type of anesthesia. Although GA was associated with more frequent drops in MBP $>20 \%$ from the baseline compared to $\mathrm{CS}$, there was no significant difference in large falls in MBP (either defined as a decline of $>$ $40 \%$ or $\mathrm{MBP}<70 \mathrm{mmHg}$ ) between GA and CS [86•, 87•, 88]. These results are important evidence that CS and GA can be equivalent methods of anesthesia in patients undergoing mechanical thrombectomy.

BP treatment in the post MT period is another important issue. Recanalization is achieved in up to $70-80 \%$ of patients $[33,34]$, which in a large portion of patients leads to a spontaneous reduction of BP. In those in which BP remains elevated, it increases the risk of hemorrhagic transformation and therefore poor functional outcome. In a study by Goyal et al., patients with intensively $(<140 / 90 \mathrm{mmHg}$ ) and moderately ( $<160 / 90 \mathrm{mmHg}$ ) lowered BP levels experienced lower mortality rates when compared to patients with permissive BP levels $(<220 / 120 \mathrm{mmHg}$ or $<180 / 110 \mathrm{mmHg}$ if IVT was administered) [78]. This is in line with the finding that higher peak values of SBP in the first $24 \mathrm{~h}$ after MT are associated with worse functional outcomes at 90 days and greater severity of hemorrhagic complications within $48 \mathrm{~h}$ after MT [89].

The studies in the field of BP management during MT have been summarized in a recent systematic review by Maier et al. The results indicate particularly that BP drops during the procedure may be associated with poor functional outcome [90••]. The data show that in the studies where the BP level was strictly maintained between 120 (140) and $180 \mathrm{mmHg}$, there was no association between the BP level and the outcome [91, 92].

\section{Low Blood Pressure in AIS}

Low BP levels are detected in about $5-10 \%$ of patients with ischemic stroke, and this was shown to be related with poor functional outcome [93, 94]. Of note, the etiology of AIS presenting low BP might be unrelated to occlusive vessel disease, but this is beyond the scope of the article.

Low BP may be triggered by conditions other than neurological ones, such as hypovolemia [95], myocardial infarction, heart failure [94], takotsubo syndrome, cardiac arrhythmia, aortic dissection, and blood loss, including retroperitoneal hemorrhage and peri-procedural hemorrhage during MT. A significant BP drop may occur during the induction phase of GA during MT, since a drop in BP is a side effect of most anesthetic medications [96]. However, not only GA but also CS causes a decline in BP $[97,98]$ (see above).

According to the latest AHA/ASA recommendations, hypotension and hypovolemia should be corrected to maintain a systemic perfusion level necessary to support organ function [56••]. It is not indicated whether colloids or crystalloids should be used. The authors, however, do not indicate the BP level below which the treatment should be initiated, how long it should be maintained, and which BP level should be a treatment goal.

One should, however, remember that excessive fluid therapy may exacerbate chronic diseases like anemia and eventually result in ischemic lesion growth [99].

Recently, Bang et al. published the results of a randomized study, evaluating the impact of phenylephrine-induced hypertension on short- and long-term outcome in patients with noncardioembolic stroke, causing a major neurologic deficit (baseline NIHSS score 4-18 points), who were ineligible for recanalization therapy (IVT or MT) or who experienced a progression of the stroke. Patients with SBP $>170 \mathrm{mmHg}$ were excluded from the study. Induced hypertension was associated with early neurologic improvement and functional independence at 90 days, without severe complications $[100 \bullet \bullet$. This is the first randomized trial in this field, which may contribute to a change in future guidelines.

\section{BP Management in Acute Ischemic Stroke Patients With and Without Hypertension}

In contrast to BP values, it is speculated that the history of hypertension may serve as a reliable predictor of stroke outcome. The presence of hypertension and related end organ damage should be accounted for in the individual overall cardiovascular risk, in general, as important determinants of both vascular and overall health.

Indeed, AIS patients with premorbid HT have an increased risk of cerebral hypoperfusion or edema with a decline or rise in BP, respectively. Moreover, patients with AIS and premorbid HT have a better prognosis at higher admission $\mathrm{BP}$ values compared with those with preexisting normotonia [101].

Recent data have also suggested that the results of BP reductions in AIS should be adjusted for premorbid hypertension.

In a Chinese trial, CATIS (China Antihypertensive Trial in Acute Ischemic Stroke), conducted among 4071 patients with non-thrombolyzed ischemic stroke within $48 \mathrm{~h}$ of onset and elevated systolic blood pressure, it was found that early 
antihypertensive treatment was not associated with a combined primary outcome, defined as death or significant disability (modified Rankin Scale score $\geq 3>2$ points), at day 14 or hospital discharge, among patients with or without hypertension. However, a history of premorbid hypertension appeared to be discriminative regarding secondary stroke prevention. In patients with pre-stroke hypertension, early antihypertensive treatment was associated with a lower rate of 3month recurrent strokes. Conversely, non-hypertensive patients treated with antihypertensives in the initial stages of AIS tended to have more recurrent strokes $(p=0.06)$ [102••]. Of note, the results of the CATIS trial should be interpreted with caution, because they may not be valid for other populations than the Chinese, where the prevalence of hypertension is high, and stroke is more common than coronary heart disease, especially in rural areas [103].

Hypertension may also modify the clinical outcome in patients undergoing a specific treatment of AIS. Available evidence shows that arterial hypertension is related to poor functional outcome after intravenous thrombolysis [104]. However, in a recently published multicentre study of ischemic stroke in patients eligible for intravenous thrombolysis (ENCHANTED study), hypertension favored neither guideline-recommended blood pressure lowering nor intensive blood pressure lowering [68••]. Importantly, this trial excluded patients with SBP > $185 \mathrm{mmHg}$.

In a recent meta-analysis on the effects of hypertension in patients undergoing mechanical thrombectomy (MT), it was shown that the presence of hypertension was associated with a lower rate of 90-day independence, regardless of the stroke severity. However, this relationship was observed in Europeans, but not in Asian and American populations. Furthermore, hypertensive patients had also a higher rate of mortality after 3 months. Interestingly, there were no associations between hypertension status and symptomatic intracerebral hemorrhage in patients with acute ischemic stroke treated with MT [105].

In summary, HT is not only one of the most important risk factors of ischemic stroke but also it may have an influence on functional outcome. However, whether it is necessary to have different BP management strategies for patients with acute ischemic stroke with or without a history of hypertension before stroke onset is unclear.

\section{Future Perspectives}

\section{Other Hemodynamic Parameters in Ischemic Stroke}

Extensive research demonstrates that arterial stiffening (reduced compliance and distensibility of arterial walls due to their structural and functional alterations, with a resultant rise in pulse wave velocity (PWV), along with the premature return of reflected pressure waves to the heart, excessive augmentation of central BP, and the transmission of flow pulsations to the periphery) has emerged as one of the earliest manifestations of vascular disease [106].

Arterial stiffness is a potent risk factor for cardiovascular complications, including stroke, in the same way as hypertension, and irrespective of BP levels.

We and other authors showed that higher PWV is associated with a worse early and late clinical outcome after ischemic stroke [107-112]. Increased PWV was also found to be associated with a higher risk of vascular death [113]. Furthermore, our team demonstrated that acute hypertensive response, the most typical hemodynamic consequence of AIS, is independently associated with increased aortic stiffness [114].

Another of our studies revealed that preserved left ventricular ejection fraction and aortic compliance are associated, independently of each other, with better neurologic outcome 10 days after ischemic stroke onset; the worst outcome was observed in patients with both stiff aorta and low ejection fraction [112].

The central augmentation index (cAIx) is a marker indirectly associated with arterial stiffness and dependent on other cardiovascular factors, such as heart rate, systolic ejection period, and peripheral vasoconstriction. Central pressure is the main drive for target organs, and therefore it seems to be a more reliable haemodynamic parameter than peripheral BP, both in physiology and pathology.

Studies on the association between cAIx and outcome after ischemic stroke are conflicting, as are studies on the relationship between central pressure parameters and cardiovascular events. Recently, we showed that a rise in the augmentation index between days 1 and 6 after stroke onset is associated with a better both early and late functional status [115]. The significance of central BP parameters may also be of great interest and still may not be fully understood, requiring further research.

Of note, BP, as one of the key components of the complex hemodynamic response during ischemic stroke, is varied and inter-personally individualized according to acute and chronic mechanisms attempting to counteract the blood compromise in the ischemic brain area. Therefore, the individualization of management protocols, depending on a more complex evaluation of cerebral and global circulation, may be important in the future.

\section{Neuromonitoring: Dynamic and Personalized Hemodynamic Control}

Recently, local and global intracranial parameters, including abnormal patterns of cerebral blood flow in cerebral large arteries or increased intracranial pressure, as assessed with transcranial Doppler (TCD), have been found to be predictive 
of tissue recovery and functional outcome after ischemic stroke [116]. In a small Chinese RCT study, adequate TCDguided BP control improved the prognosis of patients with AIS in the anterior circulation who underwent MT. For those who presented ultrasonographic signs of blood flow deceleration or features of intracranial hypertension, BP manipulation under the guidance of TCD monitoring appeared to reduce early neurological deterioration and improved the final functional outcome.

Similarly, dynamic instead of fixed BP thresholds have been postulated as a guide for individualizing hemodynamic management in AIS. In a small observational study from the USA, Petersen et al. proposed a novel approach to define the limits of autoregulation (LA) using near-infrared spectroscopy (NIRS). Continuous non-invasive NIRS neuromonitoring in response to changes in mean arterial pressure was found to identify and track the patient-specific BP range at which autoregulation was optimally functioning in individual patients after large-vessel ischemic stroke [117].

Data suggests that LA values are not stable but change over time and vary among individuals with AIS. Exceeding these individual and flexible thresholds of autoregulation was associated with worse functional outcome compared to the BP range within LA. An increased risk of sICH and neurological worsening was associated with elevated BP relative to each patient's personalized upper LA, rather than the absolute increased BP alone [118].

This novel approach to define personalized, autoregulation-based BP thresholds in acute ischemic stroke may present a better treatment strategy as compared with traditional BP management, which aims to maintain BP below the fixed thresholds, but therapies based on patients' autoregulatory statuses need further research in randomized trials.

\section{Complex Cardiopulmonary Monitoring: Confounders Influencing $\mathrm{Bp}$ and Outcome}

Finally, traditional monitoring parameters (heart rate, BP, oxygen saturation) are secondary to many compensatory mechanisms, depending on the patient and stroke baseline characteristics.

Approximately $25 \%$ of AIS are of cardiac origin [119]. Cardiac dysfunction can worsen the pre-stroke cerebral damage. An adequate cardiac output ( $\mathrm{CO}$ ) corresponds to adequate oxygen delivery. Recently, $\mathrm{CO}$ has been shown to be better associated with cerebral perfusion than blood pressure in ischemic stroke and with stroke outcome [120]. Indeed, cardiovascular complications, including acute on-chronic coronary syndrome, arrhythmias, autonomic dysfunction, and takotsubo syndrome, with or without subsequent heart failure, are observed in the majority of AIS patients within the first
$24 \mathrm{~h}$ [121]. A novel study found that multimodal brain imaging performed in acute stroke may accurately predict reduced left ventricle ejection fraction (LVEF). The arterial input function width on perfusion computed tomography has been shown to correlate with LVEF in AIS and to identify patients with a reduced LVEF and increased risk of worse clinical outcome 3 months after the event [122].

Furthermore, obstructive sleep apnea (OSA), a disorder characterized by recurrent episodes of upper respiratory tract obstruction during sleep, accompanied by intermittent hypoxia, is very common in AIS patients, with a prevalence of $61.9 \%$. Of importance, patients with AIS and OSA have been shown to demonstrate a higher SBP after an ictus, as well as a higher rate of cardiac alterations, including an increased left ventricular wall thickness and left atrial diameter [123]. Both OSA and cardiac damage play a crucial role in AIS.

Thus, metabolic and hemodynamic optimization, both at the local and global level, may need to be considered as a potent neuroprotective strategy, though RCTs are needed to determine the optimal hemodynamic approach.

\section{Conclusions}

AIS is a major medical emergency with heterogenous pathophysiology across patients and over time. Elevated BP is the most common clinical symptom recorded at stroke presentation; however, low BP may also occur, yet much less frequently.

The physiological basis for the abrupt changes in BP shortly after focal cerebral ischemia remains poorly understood. Such changes represent many mechanisms, both nonspecific and stroke related, that resolve within hours and days in the vast majority of subjects, but it remains debatable as to whether they are of therapeutic relevance.

Recent data show the importance not only of prerecanalization but also intra- and postprocedural BP and its variability.

However, measures other than BP, including stroke and patient characteristics, may need to be considered in the early evaluation of the prognosis and treatment of altered BP in AIS.

Individual parameters of cerebral circulation, such as autoregulation-derived, personalized BP range, as well as the broader aspects of hemodynamic homeostasis (cardiac output, pulse wave velocity) have also been postulated as more robust and reliable predictors of functional outcome in patients with AIS than BP alone. Advanced cerebral and systemic hemodynamic monitoring might be valuable goals in order to optimize the penumbral perfusion in AIS. 


\section{Compliance with Ethical Standards}

Conflict of Interest The authors declare no conflicts of interest relevant to this manuscript.

Human and Animal Rights and Informed Consent This article does not contain any studies with human or animal subjects performed by any of the authors.

Open Access This article is licensed under a Creative Commons Attribution 4.0 International License, which permits use, sharing, adaptation, distribution and reproduction in any medium or format, as long as you give appropriate credit to the original author(s) and the source, provide a link to the Creative Commons licence, and indicate if changes were made. The images or other third party material in this article are included in the article's Creative Commons licence, unless indicated otherwise in a credit line to the material. If material is not included in the article's Creative Commons licence and your intended use is not permitted by statutory regulation or exceeds the permitted use, you will need to obtain permission directly from the copyright holder. To view a copy of this licence, visit http://creativecommons.org/licenses/by/4.0/.

\section{References}

Papers of particular interest, published recently, have been highlighted as:

- Of importance

•- Of major importance

1. Bill F, Foundation MG. Global, regional, and national burden of stroke, 1990-2016: a systematic analysis for the Global Burden of Disease Study 2016. Lancet Neurol. 2016;18:439-58.

2. Feigin VL, Norrving B, Mensah GA. Global burden of stroke. Circ Res. 2017;120:439-48.

3. Pistoia F, Sacco S, Degan D, Tiseo C, Ornello R, Carolei A. Hypertension and stroke: epidemiological aspects and clinical evaluation. High Blood Press Cardiovasc Prev. 2016;23(1):9-18.

4. Hauer AJ, Ruigrok YM, Algra A, Dijk EJ Van, Koudstaal PJ, Luijckx G, et al. Age-specific vascular risk factor profiles according to stroke. J Am Heart Assoc. 2017;6(e005090)

5. Egan BM, Stevens-Fabry S. Prehypertension - prevalence, health risks, and management strategies. Nat Rev Cardiol. 2015;12:289300 .

6. Rothwell PM, Howard SC, Dolan E, O'Brien E, Dobson JE, Dahlöf B, et al. Prognostic significance of visit-to-visit variability, maximum systolic blood pressure, and episodic hypertension. Lancet. 2010;375(9718):895-905.

7. O'Brien E, Sheridan J, O'Malley K. Dippers and non-dippers. Lancet. 1988;332(8607):397.

8.• Kario K. Perfect 24-hr blood pressure control: up-to-date 2020. Curr Hypertens Rev. 2020;16:2-10. This article highlights the importance of best possible 24-hour blood pressure control and the need for individualized HT management.

9. Mozaffarian D, Benjamin EJ, Go AS, Arnett DK, Blaha MJ, Cushman M, et al. Heart disease and stroke statistics-2015 update: a report from the American Heart Association. Circulation. 2015. e29-322.

10. Countries MVH, Owolabi M, Olowoyo P, Miranda JJ, Akinyemi $\mathrm{R}$, Feng W, et al. Gaps in hypertension guidelines in low- and middle-income versus high-income countries. Hypertension. 2016;68:1328-37.

11. Lackland DT, Roccella EJ, Deutsch AF, Fornage M, George MG, Howard G, et al. Factors influencing the decline in stroke mortality. A statement from the American Heart Association/American Stroke Association. Stroke. 2014;45(1):315-53.

12. Perkovic V, Huxley R, Wu Y, Prabhakaran D, Macmahon S. The burden of blood pressure-related disease. A neglected priority for global health. Hypertension. 2007;50:991-7.

13. Saposnik G, Hachinski V. The pathway towards an effective reduction of stroke burden worldwide: teamwork. Lancet Neurol. 2019;18:622-3.

14. Qureshi AI, Ezzeddine MA, Nasar A, Suri MFK, Kirmani JF, Hussein HM, et al. Prevalence of elevated blood pressure in 563, 704 adult patients with stroke presenting to the ED in the United States. Am J Emerg Med. 2007 Jan;25(1):32-8.

15. Broderick J, Brott T, Barsan W, Haley EC, Levy D, Marler J, et al. Blood pressure during the first minutes of focal cerebral ischemia. Ann Emerg Med. 1993;22(9):1438-43.

16. Wallace J, Levy L. Blood pressure after stroke. JAMA. 1981;246(19):2177-80.

17. Britton M, Carlsson A, de Faire U. Blood pressure course in patients with acute stroke and matched controls. Stroke. 1986;17(5): 861-4.

18. Karaszewski B, Kwarciany M, Gąsecki D. Reply to: “Arterial stiffness, central blood pressures, wave reflections, and acute hypertensive response in stroke." Atherosclerosis. 2016;252:197198.

19. Fischer U, Cooney MT, Bull LM, Silver LE, Chalmers J, Anderson CS, et al. Acute post-stroke blood pressure relative to premorbid levels in intracerebral haemorrhage versus major ischaemic stroke: a population-based study. Lancet Neurol. 2014;13(4):374-84.

20. Jørgensen HS, Nakayama H, Christensen HR, Raaschou HO, Kampmann JP, Olsen TS. Blood pressure in acute stroke. The Copenhagen Stroke Study Cerebrovasc Dis. 2002;13:204-9.

21. Toyoda K, Okada Y, Fujimoto S, Hagiwara N, Nakachi K, Kitazono T, et al. Blood pressure changes during the initial week after different subtypes of ischemic stroke. Stroke. 2006;37(10): 2637-9.

22. Semplicini A, et al. Hypertension in acute ischemic stroke. Arch Intern Med. 2003;163:211-6.

23. Toyoda K, Okada Y, Jinnouchi J, Gotoh S, Yokoyama Y, Fujimoto S, et al. High blood pressure in acute ischemic. Cerebrovasc Dis. 2006;22:355-61.

24. Qureshi AI. Acute hypertensive response in patients with stroke pathophysiology and management. Circulation. 2008;118(2): 176-87.

25. Olsson T, Marklund N, Gustafson Y, Nasman B. Abnormalities at different levels of the hypothalamic-pituitary-adrenocortical axis early after stroke. Stroke. 1992;23:1573-6.

26. Myers MG, W NJ, Hachinski VC, J SM Plasma norepinephrine in stroke Stroke 1981;12(2):200-204.

27. Fiehler J, Cognard C, Gallitelli M, Jansen O, Kobayashi A, Mattle $\mathrm{HP}$, et al. European recommendations on organisation of interventional care in acute stroke (EROICAS). Eur Stroke J. 2016;1(3): 155-70.

28. Jansen PAF, Thien T, Gribnau FWJ, Schulte BPM, Willemsen JJ, Lamers KJB, et al. Blood pressure and both venous and urinary catecholamines after cerebral infarction. Clin Neurol Neurosurg. 1988;90(1):41-5.

29. Chamorro Á, Amaro S, Vargas M, Obach V, Cervera Á, GómezChoco $\mathrm{M}$, et al. Catecholamines, infection, and death in acute ischemic stroke. J Neurol Sci. 2007;252:29-35.

30. Olsen TS, Larsen B, Herning M, Skriver E, Lassen N. Original contributions blood flow and vascular reactivity in collaterally 
perfused brain tissue evidence of an ischemic penumbra in patients with acute stroke. Stroke. 1983;14(3):332-41.

31. Carlberg B, Asplund K, Hägg E. Factors influencing admission blood pressure levels in patients with acute stroke. Stroke. 1991 Apr;22(4):527-30.

32. Menon BK, Al-Ajlan FS, Najm M, Puig J, Castellanos M, Dowlatshahi D, et al. Association of clinical, imaging, and thrombus characteristics with recanalization of visible intracranial occlusion in patients with acute ischemic stroke. JAMA. 2018;320(10):1017-1026.

33. Froehler MT. Interhospital transfer before thrombectomy is associated with delayed treatment and worse outcome in the STRATIS registry (systematic evaluation of patients treated with neurothrombectomy devices for acute ischemic stroke). Circulation. 2017;136:2311-21.

34. Zaidat OO, Castonguay AC, Nogueira RG, Haussen DC, English JD, Satti SR, et al. TREVO stent-retriever mechanical thrombectomy for acute ischemic stroke secondary to large vessel occlusion registry. J NeuroIntervent Surg. 2018;516-524.

35. Furlan A, Higashida R, Wechsler L, Gent M, Rowley H, Kase C, et al. Intra-arterial prourokinase for acute ischemic stroke. JAMA. 1999;282(21):2003-11.

36. Karaszewski B, Jabłoński B, Żukowicz W. The salvageable brain in acute ischemic stroke. The concept of a reverse mismatch: a mini-review. Metab Brain Dis 2020;35:237-240.

37. Karaszewski B, Thomas RGR, Chappell FM, Armitage PA, Carpenter TK, Lymer GKS, et al. Brain choline concentration. Early quantitative marker of ischemia and infarct expansion? Neurology. 2010;75:850-6.

38. Karaszewski B, Wardlaw JM, Marshall I, Cvoro V, Wartolowska $\mathrm{K}$, Haga $\mathrm{K}$, et al. Early brain temperature elevation and anaerobic metabolism in human acute ischaemic stroke. Brain. 2009;132: 955-64.

39. Baron J. Perfusion thresholds in human cerebral ischemia: historical perspective and therapeutic implications. Cerebrovasc Dis. 2001;11(suppl 1):2-8.

40. Brozici M, van der Zwan A, Hillen B. Anatomy and functionality of leptomeningeal anastomoses: a review. Stroke. 2003:2750-62.

41. Bang OY, Saver JL, Buck BH, Alger JR, Starkman S, Ovbiagele $\mathrm{B}$, et al. Impact of collateral flow on tissue fate in acute ischaemic stroke. J Neurol Neurosurg Psychiatry. 2008;79:625-9.

42. Berkhemer OA, Jansen IGH, Beumer D, Fransen PSS, Berg LA Van Den, Yoo AJ, et al. Collateral status on baseline computed tomographic angiography and intra-arterial treatment effect in patients with proximal anterior circulation stroke. Stroke. 2016;768-776.

43. Dawson SL, Panerai B, Potter JF. Serial changes in static and dynamic cerebral autoregulation after acute ischaemic stroke. Cerebrovasc Dis. 2003;16:69-75.

44. Xiong L, Liu X, Shang T, Smielewski P, Donnelly J, Guo Z, et al. Impaired cerebral autoregulation: measurement and application to stroke. J Neurol Neurosurg Psychiatry. 2017;520-531.

45. Jordan JD, Powers WJ. Cerebral autoregulation and acute ischemic stroke. Am J Hypertens. 2012;25(9):946-50.

46. Arenillas JF, Cortijo E, Garc1 P, Levy EI, Jahan R, Liebeskind D, et al. Relative cerebral blood volume is associated with collateral status and infarct growth in stroke patients in SWIFT PRIME. J Cereb Blood Flow Metab. 2018;38(10):1839-1847.

47. Puhr-Westerheide D, Tiedt S, Rotkopf LT, Herzberg M, Reidler P, Fabritius MP, et al. Clinical and imaging parameters associated with hyperacute infarction growth in large vessel occlusion stroke. Stroke. 2019;50:2799-804.

48. Mechtouff L, Bochaton T, Paccalet A, Da Silva CC, Buisson M, Amaz C, et al. Matrix metalloproteinase- 9 and monocyte chemoattractant protein-1 are associated with collateral status in acute ischemic stroke with large vessel occlusion. Stroke. 2020;51:2232-5.
49. Wufuer A, Xiaoning Z. Blood pressure and collateral circulation in acute ischemic stroke. Herz. 2019;44:455-9.

50. Rusanen H, Saarinen T, Sillanpää N. The association of blood pressure and collateral circulation in hyperacute ischemic stroke patients treated with intravenous thrombolysis. Cerebrovasc Dis. 2015;39:130-7.

51. Jiang B, Churilov L, Kanesan L, Dowling R, Mitchell P, Dong Q. Blood pressure may be associated with arterial collateralization in anterior circulation ischemic stroke before acute reperfusion therapy. J Stroke. 2017;19(2):222-8.

52. Raychev R, Liebeskind DS, Yoo AJ, Rasmussen M, Arnaudov D, Brown S, et al. Physiologic predictors of collateral circulation and infarct growth during anesthesia - detailed analyses of the GOLIATH trial. J Cereb Blood Flow Metab. 2020;40(6):1203-12.

53. Christoforidis GA, Saadat N, Kontzialis M, Karakasis CJ, Slivka AP. Predictors for the extent of pial collateral recruitment in acute ischemic stroke. Neuroradiol J. 2020;33(2):98-104.

54.• Hong L, Cheng X, Lin L, Bivard A, Ling Y, Butcher K, et al. The blood pressure paradox in acute ischemic stroke. Ann Neurol. 2019;85(3):331-9. This study suggests that higher BP may result in a smaller infarct volume in patients with major reperfusion. In the case of reperfusion failure, high BP may result in increased infarct growth and an unfavorable outcome.

55. Goyal M, Menon BK, Van Zwam WH, Dippel DWJ, Mitchell PJ, Demchuk AM, et al. Endovascular thrombectomy after largevessel ischaemic stroke: a meta-analysis of individual patient data from five randomised trials. Lancet. 2016;387:1723-31.

56.• Powers WJ, Rabinstein AA, Ackerson T, Adeoye OM, Bambakidis NC, Becker K, et al. Guidelines for the early management of patients with acute ischemic stroke: 2019 update to the 2018 guidelines for the early management of acute ischemic stroke. Stroke. 2019;50:e344-418. These are the current recommendations for treatment of AIS patients.

57. Ahmed N, Audebert H, Turc G, Cordonnier C, Christensen H, Sacco S, et al. Consensus statements and recommendations from the ESO-Karolinska Stroke Update Conference, Stockholm 11-13 November 2018. Eur Stroke J 2018;4(4):307-317.

58.• Bath PM, Scutt P, Anderson CS, Appleton JP, Berge E, Cala L, et al. Prehospital transdermal glyceryl trinitrate in patients with ultra-acute presumed stroke (RIGHT-2): an ambulance-based, randomised, sham-controlled, blinded, phase 3 trial. Lancet. 2019;393:1009-20. This is a randomized controlled trial showing that pre-hospital treatment with transdermal GTN does not seem to improve functional outcome in patients with presumed stroke.

59. Shaw L, Price C, Mclure S, Howel D, Mccoll E, Younger P, et al. Paramedic initiated lisinopril for acute stroke treatment (PILFAST): results from the pilot randomised controlled trial. Emerg Med J. 2014;31:994-9.

60. Van Den Berg SA, Dippel DWJ, Hofmeijer J, Fransen PSS, Caminada K. Multicentre randomised trial of acute stroke treatment in the ambulance with a nitroglycerin patch (MR ASAP): study protocol for a randomised controlled trial. Trials. 2019;20(1):383.

61. The National Institute of Neurological Disorders and Stroke rt-PA Stroke Study Group. Tissue plasminogen activator for acute ischemic stroke. N Engl J Med. 1995 Dec 14;333(24):1581-7.

62. Vitt JR, Trillanes M, Hemphill JC. Management of blood pressure during and after recanalization therapy for acute ischemic stroke. Front Neurol. 2019;10(138):1-13.

63. Butcher K, Christensen S, Parsons M, Silva DA De, Ebinger M, Levi C, et al. Postthrombolysis blood pressure elevation is associated with hemorrhagic transformation. Stroke. 2009;41:72-77.

64. Ahmed N, Wahlgren N, Brainin M, Castillo J, Ford GA, Kaste M, et al. Relationship of blood pressure, antihypertensive therapy, and outcome in ischemic stroke treated with intravenous thrombolysis: retrospective analysis from Safe Implementation of Thrombolysis 
in Stroke-International Stroke Thrombolysis Register (SITSISTR. Stroke. 2009 Jul;40(7):2442-2449.

65. Yong M, Kaste M. Association of characteristics of blood pressure profiles and stroke outcomes in the ECASS-II trial. Stroke. 2008;39(2):366-72.

66. Stead LG, Gilmore RM, Vedula KC, Weaver AL, Decker WWBRJ. Impact of acute blood pressure variability on ischemic stroke outcome. Neurology. 2006;66(12):1878-81.

67. Silver B, Lu M, Morris DC, Mitsias PD, Lewandowski C, Chopp M. Blood pressure declines and less favorable outcomes in the NINDS tPA stroke study. J Neurol Sci. 2008;271:61-7.

68.• Anderson CS, Huang Y, Lindley RI, Chen X, Arima H, Chen G, et al. Intensive blood pressure reduction with intravenous thrombolysis therapy for acute ischaemic stroke (ENCHANTED): an international, randomised, open-label, blinded-endpoint, phase 3 trial. Lancet. 2019;393:877-88. This randomized controlled trial showed a reduced risk of hemorrhagic transformation in patients undergoing IVT treated intensively when compared to patients treated according to the guidelines over the first $72 \mathrm{~h}$ after stroke onset. This, however, did not translate into an improved clinical outcome.

69. Malhotra K, Ahmed N, Filippatou A, Katsanos AH, Goyal N, Alexandrov AW, et al. Association of elevated blood pressure levels with outcomes in acute ischemic stroke patients treated with intravenous thrombolysis: a systematic review and meta-analysis. 2019;21(1):78-90. This review and meta-analysis demonsrated higher risk of sICH and unfavorable outcome in patients undergoing IVT and higher pre- and post-stroke SBP.

70. Tomasello A, Castaño C, Blasco J, Aja L, Dorado L. Thrombectomy within 8 hours after symptom onset in ischemic stroke. N Engl J Med. 2015;372:2296-306.

71. Saver JL, Goyal M, Bonafe A, Diener H-C, Levy EI, Pereira VM, et al. Stent-retriever thrombectomy after intravenous t-PA vs. t-PA alone in stroke. N Engl J Med. 2015;372:2285-95.

72. Campbell BCV, Mitchell PJ, Kleinig TJ, Dewey HM, Churilov L, Yassi N, et al. Endovascular therapy for ischemic stroke with perfusion-imaging selection. N Engl J Med. 2015;372:1009-18.

73. Bracard S, Ducrocq X, Mas JL, Soudant M, Oppenheim C, Moulin T, et al. Mechanical thrombectomy after intravenous alteplase versus alteplase alone after stroke (THRACE): a randomised controlled trial. Lancet Neurol. 2016;15(11):113847.

74. Berkhemer OA, Fransen PS, Beumer D, van den Berg LA, Lingsma HF, Yoo AJ, et al. A randomized trial of intraarterial treatment for acute ischemic stroke. N Engl J Med. 2015;372: $11-20$.

75. Mulder MJHL, Ergezen S, Lingsma HF, Berkhemer OA, Fransen PSS, Beumer D, et al. Baseline blood pressure effect on the benefit and safety of intra-arterial treatment in MR CLEAN (multicenter randomized clinical trial of endovascular treatment of acute ischemic stroke in the Netherlands). Stroke. 2017;48(7):1869-76.

76. Maïer B, Gory B, Taylor G, Labreuche J, Blanc R, Obadia M, et al. Mortality and disability according to baseline blood pressure in acute ischemic stroke patients treated by thrombectomy: a collaborative pooled analysis. J Am Heart Assoc. 2017;6(10).

77. Goyal N, Tsivgoulis G, Iftikhar S, Khorchid Y, Fawad Ishfaq M, Doss VT, et al. Admission systolic blood pressure and outcomes in large vessel occlusion strokes treated with endovascular treatment. J Neurointerv Surg. 2017;9(5):451-4.

78. Goyal N, Tsivgoulis G, Pandhi A, Dillard K, Alsbrook D, Chang $\mathrm{JJ}$, et al. Blood pressure levels post mechanical thrombectomy and outcomes in non-recanalized large vessel occlusion patients. Neurology. 2017;89:540-7.

79. John S, Hazaa W, Uchino K, Thebo U, Hussain MS, Toth G, et al. Lower intraprocedural systolic blood pressure predicts good outcome in patients undergoing endovascular therapy for acute ischemic stroke. Interv Neurol. 2015;4:151-7.

80. Löwhagen Hendén P, Rentzos A, Karlsson J, Rosengren L, Sundeman H, Reinsfelt B. Hypotension during endovascular treatment of ischemic stroke is a risk factor for poor neurological outcome. Stroke. 2015;46:2678-80.

81. Bennett AE, Wilder MJ, Mcnally JS, Wold JJ, Stoddard GJ, Majersik JJ, et al. Increased blood pressure variability after endovascular thrombectomy for acute stroke is associated with worse clinical outcome. J NeuroIntervent Surg. 2018;10:823-7.

82. Maïer B, Turc G, Taylor G, Desilles J, Redjem H, Ciccio G, et al. Prognostic significance of pulse pressure variability during mechanical thrombectomy in acute ischemic stroke patients. J Am Hear Assoc. 2018;7:1-8.

83. Abou-Chebl A, Zaidat OO, Castonguay AC, Gupta R, Sun CJ, Martin CO, et al. North American SOLITAIRE Stent-Retriever Acute Stroke Registry. Stroke. 2014;45:1396-1401.

84. Treurniet KM, Berkhemer OA, Immink RV, Lingsma HF, Stam VMCW Der, Hollmann MW, et al. A decrease in blood pressure is associated with unfavorable outcome in patients undergoing thrombectomy under general anesthesia. J NeuroIntervent Surg. 2018;10:107-111.

85. Whalin XMK, Halenda XKM, Haussen XDC, Rebello XLC, Frankel XMR, Gershon XRY, et al. Even small decreases in blood pressure during conscious sedation affect clinical outcome after stroke thrombectomy: an analysis of hemodynamic thresholds. Am J Neuroradiol. 2017;38:294-8.

86. Simonsen CZ, Yoo AJ, Sørensen LH, Juul N, Johnsen SP, Andersen G, et al. Effect of general anesthesia and conscious sedation during endovascular therapy on infarct growth and clinical outcomes in acute ischemic stroke: a randomized clinical trial. JAMA Neurol. 2018;75(4):470-477. This is a randomized controlled trial showing that in patients undergoing thrombectomy for AIS caused by large vessel occlusions in the anterior circulation, GA did not result in worse tissue or clinical outcomes compared with CS.

87. Löwhagen Hendén P, Rentzos A, Karlsson JE, Rosengren L, Leiram B, Sundeman H, et al. General anesthesia versus conscious sedation for endovascular treatment of acute ischemic stroke. The AnStroke Trial (Anesthesia During Stroke). Stroke. 2017;48:1601-7. This randomized controlled trial shows no difference between GA and CS in neurological outcome 3 months after stroke.

88. Schönenberger S, Möhlenbruch M, Pfaff J, Mundiyanapurath S, Kieser M, Bendszus M, et al. Sedation vs. Intubation for Endovascular Stroke TreAtment (SIESTA) - a randomized monocentric trial. Int J Stroke. 2015;10(6):969-78.

89. Mistry EA, Mistry AM, Nakawah MO, Khattar NK, Fortuny EM, Cruz AS, et al. Systolic blood pressure within 24 hours after thrombectomy for Acute Ischemic Stroke Correlates With Outcome. Am Hear Assoc. 2017;6:e006167.

90.• Maïer B, Fahed R, Khoury N. Association of blood pressure during thrombectomy for acute ischemic stroke with functional outcome. Stroke. 2019;50:2805-12. This current meta-analysis highlights that BP drops during MT may be associated with a worse functional outcome. It also suggests that if strict SBP targets are achieved, no association between BP and functional outcome is noted.

91. Rasmussen M, Espelund US, Juul N, Yoo AJ, Sørensen LH, Sørensen KE, et al. The influence of blood pressure management on neurological outcome in endovascular therapy for acute ischaemic stroke. Br J Anaesth. 2018;120(6):1287-94.

92. Schönenberger S, Uhlmann L, Ungerer M, Pfaff J, Nagel S, Klose $\mathrm{C}$, et al. Association of blood pressure with short- and long-term functional outcome after stroke thrombectomy. Post hoc analysis of the SIESTA trial. Stroke. 2018;49:1451-6. 
93. Leonardi-Bee J, Bath PMW, Phillips SJ, Sandercock PAG. Blood pressure and clinical outcomes in the international stroke trial. Stroke. 2002;33(5):1315-20.

94. Wohlfahrt P, Krajcoviechova A, Jozifova M, Mayer O, Vanek J, Filipovsky J, et al. Low blood pressure during the acute period of ischemic stroke is associated with decreased survival. J Hypertens. 2015;33:339-45.

95. Kreimeier U. Pathophysiology of fluid imbalance. Crit Care. 2000;4(suppl 2):S3-7.

96. Fandler S, Stefan H, Placido H, Delgado A, Kneihsl M, Hassler E, et al. Single mean arterial blood pressure drops during stroke thrombectomy under general anaesthesia are associated with poor outcome. J Neurol. 2020;267(5):1331-9.

97. Petersen NH, Ortega-gutierrez S, Wang A, Lopez GV, Strander S, Kodali S, et al. Decreases in blood pressure during thrombectomy are associated with larger infarct volumes and worse functional outcome. Stroke. 2019;50:1797-804.

98. Valent A, Sajadhoussen A, Maier B, Lapergue B, Labeyrie M-A, Reiner $\mathrm{P}$, et al. A $10 \%$ blood pressure drop from baseline during mechanical thrombectomy for stroke is strongly associated with worse neurological outcomes. J NeuroIntervent Surg. 2020;12: 363-9.

99. Bellwald S, Balasubramaniam R, Nagler M, Burri MS, Fischer SDA, Hakim A, et al. Association of anemia and hemoglobin decrease during acute stroke treatment with infarct growth and clinical outcome. PLoS One. 2018;13(9):1-13.

100.• Bang OY, Chung J-W, Kim S-K, Kim SJ, Lee MJ, Hwang J, et al. Therapeutic-induced hypertension in patients with noncardioembolic acute stroke. Neurology. 2019;93(21):e195563 . The study suggests that phenylephrine-induced hypertension may be safe and may result in early- and long-term neurologic improvement in patients ineligible for revascularization therapy and those with progressive stroke.

101. Okumura K, Ohya Y, Maehara A, Wakugami K, Iseki K, Takishita S. Effects of blood pressure levels on case fatality after acute stroke. J Hypertens. 2005 Jun;23(6):1217-23.

102.• Zhang R, Zhong C, Zhang Y, Xie X, Zhu Z, Wang A, et al. Immediate antihypertensive treatment for patients with acute ischemic stroke with or without history of hypertension: a secondary analysis of the CATIS randomized clinical trial. JAMA Netw open. 2019;2(7):e198103. Data from a secondary analysis of the randomized clinical trial suggesting that early antihypertensive therapy may be associated with a decreased rate of recurrent stroke among patients with a history of hypertension.

103. Zhao D, Liu J, Wang M, Zhang X, Zhou M. Epidemiology of cardiovascular disease in China: current features and implications. Nat Rev Cardiol. 2019;16:203-12.

104. Zonneveld TP, Algra A, Dippel DWJ, Kappelle LJ, van Oostenbrugge RJ, Roos YBWEM, et al. The ThRombolysis in UnconTrolled Hypertension (TRUTH) protocol: an observational study on treatment strategy of elevated blood pressure in stroke patients eligible for IVT. BMC Neurol. 2015;15:1-6.

105. Yuan Z, Chen N, Zhou M, Guo J, Zhang Y, Li Y, et al. Effects of hypertension in patients receiving mechanical thrombectomy. Medicine (Baltimore). 2020;99(16):e19803.

106. Cavalcante JL, Lima JAC, Redheuil A, Al-Mallah MH. Aortic stiffness: current understanding and future directions. J Am Coll Cardiol. 2011;57(14):1511-22.

107. Gąsecki D, Rojek A, Kwarciany M, Kubach M, Boutouyrie P, Nyka W, et al. Aortic stiffness predicts functional outcome in patients after ischemic stroke. Stroke. 2012;43:543-4.

108. Gasecki D, Rojek A, Kwarciany M, Kowalczyk K, Boutouyrie P, Nyka W, et al. Pulse wave velocity is associated with early clinical outcome after ischemic stroke. Atherosclerosis. 2012;225(2):348 52.

109. Ishizuka K, Hoshino T, Shimizu S, Shirai Y, Mizuno S, Toi S, et al. Brachial-ankle pulse wave velocity is associated with 3month functional prognosis after ischemic stroke. Atherosclerosis. 2016;255:1-5.

110. Lee Y-B, Park J-H, Kim E, Kang C-K, Park H-M. Arterial stiffness and functional outcome in acute ischemic stroke. J Cerebrovasc Endovasc Neurosurg. 2014;16(1):11.

111. Matsushima H, Hosomi N, Hara N, Yoshimoto T, Neshige S, Kono R, et al. Ability of the ankle brachial index and brachialankle pulse wave velocity to predict the 3-month outcome in patients with non-cardioembolic stroke. J Atheroscler Thromb. 2017;24(11):1167-73.

112. Rojek A, Gasecki D, Fijalkowski M, Kowalczyk K, Kwarciany $\mathrm{M}$, Wolf $\mathrm{J}$, et al. Left ventricular ejection fraction and aortic stiffness are independent predictors of neurological outcome in acute ischemic stroke. J Hypertens. 2016;34:2441-8.

113. Ahn KT, Jeong J, Jin S, Kim M, Oh JK, Seong S, et al. Brachialankle PWV for predicting clinical outcomes in patients with acute stroke. Blood Press. 2017;26:204-10.

114. Kwarciany M, Gasecki D, Kowalczyk K, Rojek A, Laurent S, Boutouyrie $\mathrm{P}$, et al. Acute hypertensive response in ischemic stroke is associated with increased aortic stiffness. Atherosclerosis. 2016;251:1-5.

115. Kowalczyk K, Jabłoński B, Kwarciany M, Narkiewicz K, Gąsecki D. Changes of augmentation index early after ischaemic stroke predict functional outcome. Blood Press. 2020;29:327-335.

116. Chen H, Su Y, He Y, Zhang Y, Sun Y, Fan L. Controlling blood pressure under transcranial Doppler guidance after endovascular treatment in patients with acute ischemic stroke. Cerebrovasc Dis. 2020;49:160-9.

117. Wang A, Sheth K, Marshall R, Mampre D, Hebert R, Matouk C, et al. Autoregulation-based blood pressure optimization after large-vessel ischemic stroke using non-invasive near-infrared spectroscopy monitoring. Neurology. 2018;90(suppl 15):S21.008.

118. Petersen NH, Silverman A, Strander SM, Kodali S, Wang A, Sansing LH, et al. Fixed compared with autoregulation-oriented blood pressure thresholds after mechanical thrombectomy for ischemic stroke. Stroke. 2020;51:914-21.

119. Paciaroni M, Agnelli G, Caso V, Venti M, Milia P, Silvestrelli G, et al. Atrial fibrillation in patients with first-ever stroke: frequency, antithrombotic treatment before the event and effect on clinical outcome. J Thromb Haemost. 2005;3:1218-23.

120. Byun JI, Jung KH, Kim YD, Kim JM, Roh JK. Cardiac function and outcome in patients with cardio-embolic stroke. PLoS One. 2014;9(4):e95277.

121. Gunnoo T, Hasan N, Khan MS, Slark J, Bentley P, Sharma P. Quantifying the risk of heart disease following acute ischaemic stroke: a meta-analysis of over 50000 participants. BMJ Open. 2016;6(e009535).

122. Garcia-Esperon C, Spratt NJ, Gangadharan S, Miteff F, Bivard A, Lillicrap T, et al. Computed tomography perfusion identifies patients with stroke with impaired cardiac function. Stroke. 2020;51: 498-503.

123. Mattaliano P, Lombardi C, Sangalli D, Faini A, Corrà B, Adobbati L, et al. Impact of obstructive sleep apnea on cardiac organ damage in patients with acute ischemic stroke. J Hypertens. 2018;36(6):1351-9.

Publisher's Note Springer Nature remains neutral with regard to jurisdictional claims in published maps and institutional affiliations. 